\title{
Correction to: Integrated Research on Disaster Risks
}

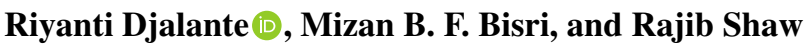

\section{Correction to:}

R. Djalante et al. (eds.), Integrated Research on Disaster Risks, Disaster Risk Reduction, https://doi.org/10.1007/978-3-030-55563-4

The original version of the book was inadvertently published with an incorrect layout in Chapter 7, and an incorrect version of Chapter 18. The layout of Chapter 7 has been corrected. The correct version of Chapter 18 has been included with one page reduced in the book and the title corrected in the Table of Contents.

The updated versions of these chapters can be found at https://doi.org/10.1007/978-3-030-55563-4_7

https://doi.org/10.1007/978-3-030-55563-4_18 